\title{
Lambda Light Chain Measurement
}

National Cancer Institute

\section{Source}

National Cancer Institute. Lambda Light Chain Measurement. NCI Thesaurus. Code C147384.

The determination of the amount of lambda light chain present in a sample. 